\title{
Women eat more rice and banana: the influence of gender and migration on staple food choice in East Africa
}

\author{
Aurélie Bechoff ${ }^{a *}$, Lora Forsythe ${ }^{a}$, Maria $\mathrm{Njau}^{b}$, Adrienne Martin ${ }^{a}$, Gaspar \\ Audifas ${ }^{c}$, Adebayo Abass $^{c}$, Keith Tomlins ${ }^{a}$ \\ ${ }^{a}$ Natural Resources Institute (NRI), University of Greenwich, Central Avenue, Chatham, \\ ME44TB, UK; ${ }^{b}$ Independent consultant; ${ }^{c}$ International Institute for Tropical Agriculture \\ (IITA), Dar es Salaam, Tanzania \\ *Address correspondence to Dr Aurélie Bechoff https://orcid.org/0000-0001-8141-4448, \\ Natural Resources Institute (NRI), University of Greenwich, Central Avenue, Chatham, \\ ME44TB, UK Email: a.bechoff@gre.ac.uk
}

This work was funded by the CGIAR Research Program on Roots, Tubers and Bananas (RTB) and supported by CGIAR Trust Fund contributors. 


\title{
Women eat more rice and banana: the influence of gender and migration on staple food choice in East Africa
}

\begin{abstract}
An original approach was used to examine how staple food choice differs by gender and migration: this consisted of a quantitative survey (6 locations with urban consumers from various economic classes $(n=123)$ ), a qualitative in-depth interview with a subset of those consumers $(n=18)$, and focus group discussions $(n=13)$. Men and women had similar results in terms of their preferred staple food choice attributes; yet women indicated consuming more rice and banana, and men, more maize and cassava (Chi-squared test; $p<0.05$ ). Migration status and life stage (formative or adult years) also influenced the type and diversity of staple crops reported.
\end{abstract}

Keywords: food choice, staple, gender, urban migration, mixed methods

\section{Introduction}

There is currently in African cities a growing food consumption driven by economic growth (Potts 2016). This constitutes a significant part of the food produced and imported (Vorley and Lançon 2016). The growing urban market has an impact on trade in the urban food supply leading to changes in the balance of imports, exports and demand for domestic foods. Some staples such as rice are mostly imported, whilst others such as cassava, maize, or banana tend to be locally grown. Import restrictions by governments are seeking to encourage domestic production of food crops including traditional staples such as cassava, which has been identified as one of the emerging market orientated commodities in Tanzania and elsewhere in Africa (Bennett et al. 2014).

To understand which staple foods people preferentially would consume and in which form(s), measuring consumer preferences has been the common approach. Food acceptance for staples 
such as cassava (Tomlins, Sanni, et al. 2007; Bechoff et al. 2018), rice (Tomlins, Manful, et al. 2007), maize (De Groote and Kimenju 2008), sweet potato (Lagerkvist et al.

2016; TomlinsNdunguru et al. 2007) has been reviewed in the sub-Saharan African context. These previous studies, while providing insights into preferences in the context of hedonic preferences and willingness to pay of a specific set of staples, did not however explore the wider context of how people make food choices in relation to other staples they consume.

Research elsewhere (Furst et al. 1996; Keane and Willetts 1994; Turner et al. 2017) suggests people's life course experiences have a major influence on food choice that includes ideals, personal factors, resources, social contexts and the food environment. These influences can inform the development of personal systems for making food choices that incorporate value negotiations and behavioural strategies. These behavioural strategies can be influenced by factors such as migration to the urban centres with more diverse food sources compared to rural areas where consumption of staples is traditional and food choices are restricted (Kearney 2010). This has nutritional implications, but also challenges as to whether individuals and families maintain the consumption of traditional staples such as cassava or whether they switch to other 'more modern' staples consumed in urban areas such as rice and maize.

Gender is expected to have an impact on food choice, and evidence from other countries in Africa show that women play an important role in food purchase decisions related to cassava (Forsythe, Posthumus, and Martin 2016; Kaitano and Martin 2009). Women have been reported to have differing attitudes to men regarding food choices and this will influence 
household consumption, particularly for children (Wardle et al. 2004). Income levels are also likely to influence food choice (Furst et al. 1996).

Our study examines staple food choice in people's daily diet. Our approach is mainly from a quantitative perspective but includes insights from a qualitative and gender study. We used a mixture of consumer research, social science, and food science methodologies to understand people's choices of staple crops. The analysis provides an understanding of people's food choice for several staples, and how it may differ by gender and other factors of social difference such as life stage and migration status.

\section{Methods}

\section{Study area}

The study area was the capital city of Tanzania, Dar es Salaam. Dar es Salaam is the $11^{\text {th }}$ largest city in Africa with a growth rate of 6\%. The city has grown from 2.5 million in 2002 to 5.1 million in 2018, which means a doubling of the population (NBS, 2018). The population of Dar es Salaam is slightly older than the national average with $78 \%$ of the population aged 35 years or below, compared to $84 \%$ for Tanzania as a whole (NBS, 2014). The last official census was conducted in 2012 and identified the population of three districts in Dar es Salaam: Kinondoni (1.7 million people); Temeke (1.3 million), and Ilala (1.2 million) at the time. In 2015, Dar es Salaam was divided further into two new districts: Ubungo (0.8 million) previously under Kinondoni and Kigamboni previously under Temeke.

Our research took place in Kinondoni district. The district has a $42 \mathrm{~km}$ long coastal stretch which includes the Swahili fishing communities (a mix of Arab and the Zaramo, a local 
ethnic community found along the coast), along with numerous houses of the wealthy elite who may have differing food cultures and food choices. The remaining area is inhabited by people of low to middle income working in small businesses or in nearby industrial areas. A profile of the Kinondoni district (2016) reports that $61 \%$ of its population work in the private sector, $35 \%$ are self-employed, and $4 \%$ are public sector employees.Kawe has a population of 94,535 and a population density of 50 persons per hectare.

The 2012 Population and Housing Census in Tanzania reported that urbanisation is taking place rapidly, increasing from $4.7 \%$ to $10.8 \%$, and 7.8 million Tanzanians live outside their place of birth. Dar es Salaam has strong economic pull and has positive net migration. Dar es Salaam, as the largest urban centre in the country, has the highest proportion of in-migration at 30 percent and highest level of urbanisation (3\%) (Table 1). The regions with highest outmigration (as a percentage of non-migrants) are Kusini Unguja (53\%), Pwani (43\%), Shinyanga (43\%) and Kilimanjaro (39\%). The regions with lowest out-migration are Mbeya (10\%), Manyara (10\%) and Mjini Magharibi (10\%) (NBS 2015).

\section{Staple foods in Tanzania}

Tanzanian diets typically consist of one or two staple foods such as maize, teff, cassava, yam, sweet potato and banana. These are complemented with legumes, animal products and green leafy vegetables.

Ugali - a cooked dough made from flour - is the food base for meals in Tanzania. Ugali can be made from a variety of flours from staples such as maize, cassava, sorghum, millet or banana. Flours are added to boiling water and stirred into a paste. Flours may be used either singly or mixed. In Dar es Salaam, the most common type of ugali is prepared using maize 
flour, either de-husked maize known as sembe or non-de-husked maize known as dona. Long-fermented traditional brown dried cassava is called makopa. Makopa is milled to flour for preparing cassava ugali. Cassava ugali can also be made with unfermented cassava flour called High Quality Cassava Flour (HQCF) that is of better quality (i.e. white colour, less odour) overall than makopa. Some common types of ugali in Dar es Salaam are listed in 
Table 2. Ugali is typically consumed with a dish of beans and/or meat/fish/chicken and vegetables such as spinach, collard greens, amaranth greens or okra. Along the coast, coconut milk, tamarind, mangoes and seafood are used in various dishes with ugali. Maize and cassava are mostly consumed as ugali, banana can also be consumed as such, whilst rice is consumed as boiled grains.

\section{Design of the study}

This study was designed as an original approach that consisted in two complementary phases: the first phase was a semi-quantitative study that consisted of numerous individual interviews about staple food choices and the second phase was a qualitative in-depth interview (IDI) with a subset of those respondents, as well as focus group discussions (FGD).

In the quantitative study, we initially conducted a focus group. The focus group's aim was to elicit views related to staple food choice in Tanzania that would help with the design of the quantitative questionnaire. In addition, the focus group participants helped shape the questions for the food choice questionnaire for the 9 dimensions of food in order to adapt the questions to Tanzanian urban consumers. Participants of the focus group $(n=9)$ were from various areas of Tanzania that have different types of staple foods. After the questionnaire was designed, enumerators were trained and the questionnaire was validated in a dummy trial before its actual delivery. Respondents, also called 'consumers' ( $n=123)$ were individually interviewed at six different locations in Dar Es Salaam using the central location method (Meilgaard, Carr, and Civille 2006) ( 
Table 3). The sample size of the quantitative survey was based on customary sample sizes used in the field of consumer research: the usual number of consumers considered in hedonic testing conducted with CATA testing is 100-120 (Ares et al. 2014). A consumer acceptance survey with cassava ugali and sembe was also conducted but the results are not reported here. Restaurants that had consumers of different social classes were purposely selected based on the socio-demographic spread (e.g. $80 \%$ of low-middle class and $20 \%$ of wealthier class) and on local knowledge to include consumers of different gender, migration profiles and poverty levels. Given the difficulties of sampling in urban environments this was a simple and effective strategy.

An index (Schreiner 2016) for Tanzania was used to measure the poverty level of those urban consumers. The Poverty Probability Index (PPI) contains 10 questions on household characteristics and asset ownership tailored to a specific country which shows the likelihood that the household is living below the poverty line. Consumers $(n=123)$ were asked about the food choice for their main staple and other main crops such as maize, rice, and cassava etc. Information was elicited from each consumer regarding demographics, wealth, education, staple, food habits such as staple, main crop's form of consumption and frequency.

We also sought to introduce a new and simplified tool to measure food choice related to cassava in Africa. Steptoe, Pollard and Wardle 1995 developed a method for measuring the various motives underlying the selection of food that covered a range of choice factors that included health, mood, convenience, sensory appeal, natural content, price, weight control and familiarity (Steptoe et al. 1995). In the original method, scores from 1-5 were given to 36 different attributes relating to 9 food choice-related factors: health, mood, convenience, sensory appeal, natural content, price, weight control, familiarity, ethical concern. In our 
study, the method was simplified by using the Check-All-That-Apply (CATA) method (Dooley, Lee and Meullenet 2010) based on presence (1) or absence (0) (binary scoring) instead of the 5-point score used by (Steptoe et al. 1995) for the 9 dimensions of food choice.

All spoken interviews were conducted in English or in Swahili and the score sheets and questionnaires were written in English using the Kobo Toolbox Application on an Android tablet (Belliveau 2016). Trained enumerators assisted the respondents when required. The interview procedure lasted no more than 30 minutes including an ugali tasting session (information not included here).

In the qualitative study and a second field visit to Tanzania, the study sampled a sub-set of individuals for the IDIs from the first phase. For this study, individuals for the IDI were randomly selected from the consumer lists used in the Kawe Old Market and Tamarind locations used as the sample area in the first phase. The IDIs with respondents were semistructured and based on a discussion guide around food choice in childhood, during migration and after migration. The sample size of qualitative studies depends on the level of detail required and is variable, but usually around 15-25 people (Marshall 1996).

There were 18 in-depth interviews ( 8 men, 10 women) that took place in private spaces in people's homes, places of work, restaurants or other locations in their community. Demographic information of the IDIs is provided in 
Table 4. In addition to the IDIs conducted with respondents, a FGD was conducted with a church group of 8 men and women ( 1 man, 7 women) and additional IDIs with food sellers conducted during market visits. In total, seven food sellers were interviewed (5 women and two men). Three food sellers interviewed were between 21-29 years and three between 20-39 years, and one was 65 years.

\section{Ethics}

This study has been assessed and approved by the University of Greenwich Research Ethics Committee. Consent was sought from participants in this study. Participants were informed about the study and explained that their participation was entirely voluntary, that they could stop the interview at any point and that the responses would be anonymous. A consent form was signed.

\section{Statistical Analysis}

Statistical analysis of the quantitative survey was carried out using SPSS (V 23.0) or XLSTAT (V 5.2, Addinsoft) software. Analysis of variance (mixed effect model) for continuous data and Chi-squared analysis for counts were used to assess significant relationships between different genders, socio-demographic factors, and staple food choice for the respondents interviewed $(n=123)$. After transcribing the qualitative survey data, analysis was carried out using manual coding for the various key-concepts such as migration and gender, age, and socio-economic level and led to an interpretation of the data supported with direct quotes from interviewees. 


\section{Results}

\section{Description of the characteristics of male and female interviewees}

The effect of gender on socio-demographic factors (Table 5) was reported for the

quantitative survey. There were no significant differences between men and women in terms of age, education, marital status, size of the household, having children under 18 living at home, and children attending school. Also, men and women were not different in terms of the job classification. Migration status and number of years in Dar es Salaam did not differ, nor did the area where men and women came from. With regard to indicators of poverty level, there were no gender differences in owning different goods such a car, motorbike, bicycle, fridge, TV, radio, tables, lanterns and having electricity. Also, in terms of fuel using for cooking and house construction there were no differences. Hence the Poverty Probability Index (PPI ) of both men and women was similar.

However, there were gender differences in terms of owning a house and owning 'none of the above' (this includes house, car, motorbike, and bicycle). Based on the number of counts (frequency) there were fewer house owners who were women; and more women indicated that they owned 'none of the above'. In conclusion, there did not appear to be wealth differences between men and women, however women tended to have slight less ownership of the goods and this means that gender inequalities should be further explored.

Overall PPI was also not linked with staple choice (data not shown) and this indicates that poverty level did not have a major effect on food choice of staples. This can be explained because staples are usually the most basic food in a family and wealth would be expected to be related to other more expensive food items. 


\section{Differences between men and women in terms of the attributes of staple food choice.}

We measured the various motives underlying the selection of food that covered a range of choice factors that included health, mood, convenience, sensory appeal, natural content, weight control and familiarity for staples by gender (Table 6). Men and women were asked to tick the most important attributes for their main staple. There were no gender differences in terms of all the attributes (22). One attribute however - 'can be used in many different dishes' - showed weak evidence of a difference ( $\mathrm{p}$ value of 0.055 ). This indicates that female respondents may be less sensitive to the versality of the staple compared to males and this seems contradictory. The IDIs confirmed that men do not prepare foods in the home, unless they are single and live alone. Since women are generally the ones cooking, they may be more sensitive to staples' cooking abilities, compared to men but the opposite is found here. This may be because women have a better knowledge of cooking and know that various staples have to be cooked and prepared in a different manner and staple's versality is not a priority to them.

\section{Staple foods and migration}

Quantitative and qualitative interviews showed that there were differences in staple foods consumed in interviewees' place of origin as shown on the map of Tanzania (Figure 1). Cassava is the staple food of the south and northern parts of the country around the Lake Zone, maize in the central areas, and banana in the northern areas and along the coast.

The qualitative study reported that the word for traditional food was referred to as food from asili, a Swahili word meaning a person's origin, roots, birth or essence. It can also imply a 
physical place such as the place of one's birth or childhood, or to their cultural heritage that is not necessarily rooted to particular spaces.

Over a total of 123 people interviewed in the quantitative study, only one person reported being originally from the capital (Dar es Salaam). Interviewees came from 22 regions of the country (Figure 1). For example, Kilimanjaro - a region where banana is a staple represented $14 \%$ of the interviewees and this partially explains the high consumption of banana among the female newcomers. Other banana eating areas were Arusha, Kagera, and Kilimanjaro.

\section{Changes in staple food preferences following migration of men and women}

Differences between men and women were explored in terms of staple consumption, form and frequency of consumption. Ugali is generally eaten daily once to three times a day and more commonly for lunch. According to Table 7, women and men mainly did not differ in the form or frequency they eat their staple, maize, rice, and cassava. There was a significant difference only for the ugali form that was more commonly eaten by men than by women.

However there was a significant difference $(\mathrm{p}<0.05)$ in the type of staple with respect to gender as illustrated in Figure 2: type of staple crops did not only differ between men and women during their formative years (up the age of 16) but the differences were maintained at an adult age for the different respondents interviewed. Banana and rice were staples for more women than men and maize was a staple for more men than women. 
Figure 2 indicates the staple crops of different groups of migrants by gender: people interviewed were divided into four groups: newcomer migrants (in Dar es Salaam for less than 7 years), settling-in migrants (in Dar for more than 7 years) and over the age of 16 yearold at the time of migration, settled young (arriving in Dar between the age of 5 and 16 yearold) and 'natives' (born or been in Dar before the age of 5). We observed that during the formative years, female migrants (newcomers, settling-in migrants, settled young, and 'natives') reported 5 to 6 different staples and this shows that staple background of the female interviewees was diverse (Figure 2-A). As adults, the current staples were more diverse for the female newcomer migrants than for the settled young and native groups on average (Figure 2-B). Consumption of banana and cassava which are traditional crops from the region of origin of migrants steadily reduced with the settling stage (Figures 2-A\&B). Maize which is the most popular staple in Dar es Salaam was on average a less important staple in the formative years (up to the age of 16) but became more prevalent in the current years.

Men indicated a less diverse range of staples consumed than women: during the formative years (Figure 2-C), the number of staples mentioned was over 5 for all groups but the Dar Es Salaam 'natives' only reported 2 staples: rice and maize. In adulthood and current reporting (Figure 2-D), the diversity of staples considerably reduced in men and there were also less staples in the group of 'natives': maize and rice were the main two staples reported. Banana was a minor staple for male interviewees overall. Cassava was a staple crop during the formative years of newcomers, 'settling-in migrants' and 'settled young' interviewees but was less mentioned as consumed during adult years (Figure 2-D). 
Overall for men and women, the consumption of cassava decreased for the migrants who came to Dar Es Salaam before the age of 16 most likely because cassava is not a major staple in Dar Es Salaam.

IDIs also confirmed those results: with regard to staple food consumption, independent of gender, it was clear that maize consumption increased in adulthood, and after moving to Dar es Salaam, compared to the interviewee's earlier years of life when a larger variety of crops were consumed in the formative years, such as banana, cassava, millet, potato, and wheat but in terms of current staples, it seems that the diversity was lost and the main staples reported are maize and rice. We should note however that among the interviewees, people commonly ate different types of ugali depending on seasons and availability. Flours from different crops were also mixed. Therefore, people in Dar es Salaam consume a range of ugalis from a mix of different flours throughout the year.

In terms of changes in staple food and ugali consumption, the IDIs further reported that the majority of interviewees started to consume sembe and rice after moving to the city. According to the people interviewed, these foods represent more 'modern' food that is related to urban living, as they are more easily prepared and accessed than traditional staples

"I started eating more sembe once I moved here. People in the city like milled maize [sembe] but not in the villages. It's the environment you have to get used to it. No one has time to make flour like in the villages" (male, 50-59 years, Iringa).

In accordance with the quantitative study, the qualitative study also found a notable decline in the range of staples consumed among the interviewees while in Dar es Salaam. However, 
the qualitative study produced additional findings in that migrants back in their village of origin did not have one staple food, but they consumed a range of different staples. The range of products makes it difficult for people to quantify their food habits retrospectively. Furthermore, some interviewees continued to consume the foods - including staples - from their home region after moving to the city. This was because these individuals were committed to consuming healthy foods and also foods that represented their traditions.

\section{Discussion}

Previous studies similarly showed that migrants adapted their choice of food to their new environment over time: Renzaho and Buns (2006) described how sub-Saharan African migrants to Australia switched from their traditional diet to a processed fast food diet with negative consequences on health and obesity. According to Oniang'o, Mutuku, and Malaba (2003) urbanisation is influencing consumer preferences away from traditional foods towards processed foods, which is contributing to obesity and increased diabetes and other nutritionrelated non-communicable diseases in urban areas across the continent. The influence of childhood culinary experience on migrants in adult life was also reported by WeisbergShapiro \& Devine (2019): food choices trajectories established in childhood remained, but the amount and variety of food eaten after migration increased in Dominican women who moved to the USA. Van Hook et al. (2018) reported that the timing of arrival was important in adjusting to the new diet and adopting unhealthy habits: Mexican migrants to the USA who arrived young (up to 11 years-old) had less healthy diets than adult arrivals (25+ years). A hypothesis is that adults that already had an established diet in their country of origin would spend more effort to maintain this diet (which is healthier than the US diet). In our present study, people migrated at different stages of life, but migration was preferably 
undertaken whilst people were young and before they settled to have their family. We showed a progressive adaptation to the most commonly consumed staples in the city but in contrast to Renhazo \& Bun's study, traditional staples were still available in Dar es Salaam therefore the migrants in our study could keep their traditional diet from their region of origin if they wished.

A study about diet transition in China (Chang et al. 2018) showed that gender and socioeconomic class as well as age had an influence on dietary and staple diversity. Comparing households with male and female members preparing food they showed that those had more diverse staples than households with male-only food preparation. In addition to gender, the age of the person preparing the food also positively influenced on the diversity of staples: older household members tended to consume more diverse staple foods than younger members. A possible reason is that older people could be more attached to their region of origin where staple foods remain more diverse. In sub-Saharan African settings as opposed to China, women often have the sole responsible for food preparation: Hyder et al. (2005) reported that food preparation was the principal activity of women in rural areas of Bagamoyo district, Tanzania and Kwale district, Kenya. Our study suggests that food preparation is still an important activity of women living in major cities such as Dar es Salaam. This is a major difference with the study by Chang et al. 2018 where men and women were both involved in food preparation. Because men were not involved in food preparation in Dar es Salaam, a caveat may be that there may have been a bias with men not remembering their major staple food (s). Although this seems logical, in practice, it is tricky to prove whether being involved in food preparation plays on the memory of staple foods eaten. We should however keep in mind that "the topic of food and migration is broad and cannot be considered in isolation, but should be situated within broader questions of the 
interplays between food and ethnicity, identity, globalization, memory....”(Abbots 2016). Understanding food choice and gender associated with migration is therefore complex because of the interweaving of a number of sociological factors.

\section{Conclusions}

Migration and urbanisation were shown to impact staple food consumption. The type of staple (cassava, maize, sorghum and/or millet, rice, banana etc.) that people consumed was profoundly influenced by their region of origin. However, after migration to Dar es Salaam, people typically adopted the food culture of the city over time, which mainly consists of sembe, a dehulled maize-based ugali of white colour that is categorised as a 'modern food'. Diversity of staples was less in adult years than in formative years and this may be because in younger years people had not yet migrated to the city and therefore the 'asili' (place of origin) still had a strong influence on the choice of staples. Women consumed more rice and banana, and men consumed more maize and cassava. An explanation could be that Ugali made from maize in Dar es Salaam is commonly viewed as a food consumed by men, because it is needed for strength ('hard food'). An explanation given by respondents was that women were perceived to undertake less physically demanding activities after they migrate to the capital, because they may move away from farm work, and are therefore more likely to prefer and consume rice and banana that are considered to be 'soft food'. Social norms also played an important role in influencing migrants' shift towards sembe as their staple food as they moved to Dar es Salaam. Changes in staple food habits in urban areas may also illustrate a wider change in cultural identity and this should be further explored. 


\section{Acknowledgments}

This research was undertaken as part of, and funded by, the CGIAR Research Program on Roots, Tubers and Bananas (RTB) and supported by CGIAR Trust Fund contributors https://www.cgiar.org/funders/. The views expressed are however those of the authors. The authors would like to thank Dr. Thierry Tran from the RTB program for reviewing the manuscript. We thank the Hossana Ngonyani from IITA, Tanzania and the enumerators (Anyes James Pius, Jackline Sebastani, Happiness Lema, Joan Paula, Alimelda Clement, Victor Mongi, Vitalis Mwandesite, Elizabeth Masaga and Newton Deogratius). We are grateful to the men and women who gave us of their time to answer the interviews.

\section{References}

Abbots, E.-J. 2016. Approaches to Food and Migration: Rootedness, Being and Belonging. In The Handbook of Food and Anthropology, ed. W.J. Klein and IJ. Watson, 115-132. London: Bloomsbury .

Ares, G., Tárrega, A., Izquierdo, L. and S.R Jaeger. 2014. Investigation of the number of consumers necessary to obtain stable sample and descriptor configurations from checkall-that-apply (CATA) questions. Food Quality and Preference 31: 135-141.

Bechoff, A., U. Chijioke, A., Westby, and K.I. Tomlins. 2018. 'Yellow is good for you': Consumer perception and acceptability of fortified and biofortified cassava products. PloS One 13(9): p.e0203421.

Belliveau, J. 2016. Humanitarian access and technology: opportunities and applications. Procedia Engineering 159: 300-306.

Bennett, B., D. Naziri, D. Mahende, and E. Towo. 2014. Driving demand for cassava in Tanzania: The next steps. F1000Research, 3. https://gatesopenresearch.org/documents/3-360

Brennan, J., J.R. Brennan, A. Burton, A.R. Burton, and Y.Q. Lawi. 2007. Histories from an Emerging African Metropolis: Histories from an Emerging African Metropolis. Dar es Salaam: African Books Collective.

Chang, X., R.S. DeFries, L. Liu, and K. Davis. 2018. Understanding dietary and staple food transitions in China from multiple scales. PloS One 13(4): p.e0195775.

De Groote, H., and S. Chege Kimenju. 2008. Comparing consumer preferences for color and nutritional quality in maize: Application of a semi-double-bound logistic model on urban consumers in Kenya. Food Policy 33 (4): 362-370. 
Forsythe, L., H. Posthumus, and A. Martin. 2016. A crop of one's own? Women's experiences of cassava commercialization in Nigeria and Malawi. Journal of Gender, Agriculture and Food Security 1 (2):110-128.

Furst, T., M. Connors, C.A. Bisogni, J. Sobal, and L.Winter Falk. 1996. Food choice: a conceptual model of the process. Appetite 26 (3): 247-266.

Hyder, A.A., S. Maman, J.E. Nyoni, S.A. Khasiani, N. Teoh, Z. Premji, and S. Sohani. 2005. The pervasive triad of food security, gender inequity and women's health: exploratory research from sub-Saharan Africa. African Health Sciences 5(4): 328-334.

Kearney, J. 2010. Food consumption trends and drivers. Philosophical transactions of the Royal Society B:Biological Sciences, 365, 2793-2807.

Kaitano, V., and A. Martin. 2009. Gender and diversity issues relating to cassava production and processing in Malawi. C: AVA internal report, unpublished. Chatham, UK: Natural Resources Institute, University of Greenwich.

Keane, A., and A. Willetts. 1994. Factors that affect food choice. Nutrition \& Food Science 94 (4): $15-17$.

Lagerkvist, C.J., J. Okello, P. Muoki, S. Heck, and G. Prain. 2016. Nutrition promotion messages: The effect of information on consumer sensory expectations, experiences and emotions of vitamin A-biofortified sweet potato. Food Quality and Preference 52: 143-152.

Marshall, M.N., 1996. Sampling for qualitative research. Family Practice 13(6): 522-526.

Meilgaard, M.C., B.T. Carr, and G.V. Civille. 2006. Sensory Evaluation Techniques. Boca Raton: CRC Press, https://doi.org/10.1201/9781439832271

NBS, National Bureau of Statistics. 2019. Tanzania in Figures. 2018. National Bureau of Statistics Dodoma June 2019. 94pp.

NBS. National Bureau of Statistics. 2014. Basic Demographic and Socio-Economic Profile Report Tanzania Mainland, April 2014 The United Republic of Tanzania.

NBS. National Bureau of Statistics. 2015. 2012 Population and Housing Census. Migration and Urbanisation report 2015. The United Republic of Tanzania.

NBS. National Bureau of Statistics. 2016. Basic Demographic and Socio-Economic Profile Report Dar es Salaam region. The United Republic of Tanzania.

Oniang'o, R.K., J.M. Mutuku, and S.J. Malaba. 2003. Contemporary African food habits and their nutritional and health implications. Asia Pacific Journal of Clinical Nutrition 12 (3): 231-236.

Potts, D. 2016. Debates about African urbanisation, migration and economic growth: what can we learn from Zimbabwe and Zambia? The Geographical Journal 182 (3): 251-264.

Renzaho, A. M.-N., and C. Burns. 2006. Post-migration food habits of sub-Saharan African migrants in Victoria: A cross-sectional study. Nutrition \& Dietetics 63(2): 91-102.

Schreiner, M. 2016. Tanzania: A simple poverty measurement scorecard. Progress Out Of Poverty. Accessed February 25, 2019. http://www.progressoutofpoverty.org/country/tanzania

Shayo, R. and A. Martin. 2009. Gender and Diversity Situational Analysis: Tanzania Country Report. Chatham, UK: Natural Resources Institute for C:AVA and Catholic Relief Services.

Steptoe, A., Pollard, T.M. and, J. Wardle. 1995. Development of a measure of the motives underlying the selection of food: the food choice questionnaire. Appetite, 25(3): 267284.

Tomlins, K., J. Manful, J. Gayin, B. Kudjawu, and I. Tamakloe. 2007. Study of sensory evaluation, consumer acceptability, affordability and market price of rice. Journal of the Science of Food and Agriculture 87 (8): 1564-1575. 
Tomlins, K., G. Ndunguru, K. Stambul, N. Joshua, T. Ngendello, E. Rwiza, R. Amour, B. Ramadhani, A. Kapande, and A. Westby. 2007. Sensory evaluation and consumer acceptability of pale-fleshed and orange-fleshed sweetpotato by school children and mothers with preschool children. Journal of the Science of Food and Agriculture 87 (13): 2436-2446.

Tomlins, K., L. Sanni, O. Oyewole, A. Dipeolu, I. Ayinde, K. Adebayo, and A. Westby. 2007. Consumer acceptability and sensory evaluation of a fermented cassava product (Nigerian fufu). Journal of the Science of Food and Agriculture 87(10): 1949-1956.

Turner, C., Kalamatianou, S., Drewnowski, A., Kulkarni, B., Kinra, S., and S. Kadiyala 2019. Food Environment Research in Low-and Middle-Income Countries: A Systematic Scoping Review. Advances in Nutrition (Bethesda, Md.). ISSN 2161-8313 DOI: https://doi.org/10.1093/advances/nmz031

Van Hook, J., S. Quirós, M. Dondero, and C.E. Altman 2018. Healthy Eating among Mexican Immigrants: Migration in Childhood and Time in the United States. Journal of Health and Social Behavior 59(3): 391-410.

Vorley, B. and F. Lançon. 2016. Food consumption, urbanisation and rural transformation: the trade dimensions. London: IIED.

Wardle, J., A.M. Haase, A. Steptoe, M. Nillapun, K. Jonwutiwes, and F. Bellisie. 2004. Gender differences in food choice: the contribution of health beliefs and dieting. Annals of Behavioral Medicine 27(2): 107-116.

Weisberg-Shapiro, P., and Devine, C., 2019. "Men like to Eat More Rice and Beans and Things like That": The Influence of Childhood Experience and Life Course Events on Dietary Acculturation. Ecology of Food and Nutrition 5: 1-17. 
Table 1. Migration statistics for Dar es Salaam

\begin{tabular}{rcc|rrr}
\hline \multicolumn{2}{c|}{2002} & \multicolumn{3}{|c}{$\mathbf{2 0 1 2}$} \\
\hline In-migrants & $\begin{array}{c}\text { Out- } \\
\text { migrants }\end{array}$ & $\begin{array}{c}\text { Net } \\
\text { migrants }\end{array}$ & In-migrants & $\begin{array}{c}\text { Out- } \\
\text { migrants }\end{array}$ & Net migrants \\
$1,208,479$ & 237,446 & 971,033 & $2,266,013$ & 269,126 & $1,996,887$ \\
& & & $(30.8 \%)^{*}$ & $(3.7 \%)^{*}$ & \\
\hline
\end{tabular}

*\% of national average

Source: NBS, 2015 
Table 2. Types of Ugali in Tanzania

Type of $U$ gali $\quad$ Description

Photo

Sembe Made from white (de-husked) maize flour.

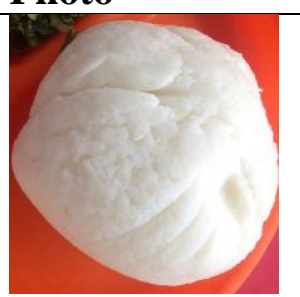

Dona

Made from maize flour with the husks. It has a cream

to brownish colour.

Cassava-ugali Whitish-cream colour ugali made from high quality made with HQCF cassava flour. HQ-ugali can be made also from high quality cassava flour mixed with maize flours.
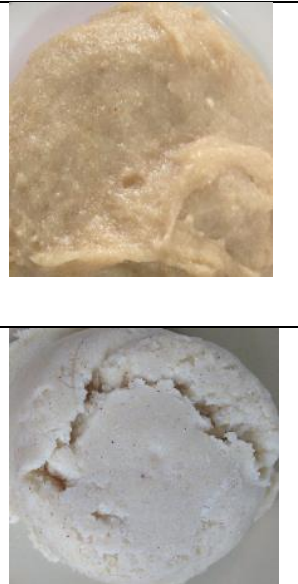

Cassava-ugali made with

Makopa flour
Traditional ugali made from flour of makopa fermented for several days and sun-dried with a dark brownish colour

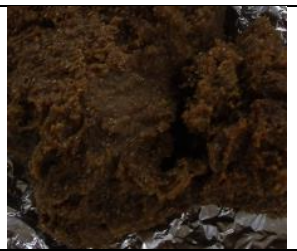


Table 3. Locations ( $n=6)$ and number of interviewees $(n=123)$ (quantitative survey)

\begin{tabular}{lll}
\hline Location & $\begin{array}{l}\text { Income level of } \\
\text { interviewees }\end{array}$ & Number of people interviewed \\
\hline 1.Kawe New market location1 & Low-medium & 15 \\
2.Kawe New market location2 & Low-medium & 34 \\
3.Kawe Old Market & Low-medium & 16 \\
4.Kawe Tanganyika peelers & Low-Medium & 39 \\
5.Kawe Zanzibar restaurant & Medium & 14 \\
6.Tamarind restaurant & High & 5 \\
\hline
\end{tabular}


Table 4. Key demographic characteristics of consumer IDIs $(n=18)$ (qualitative survey)

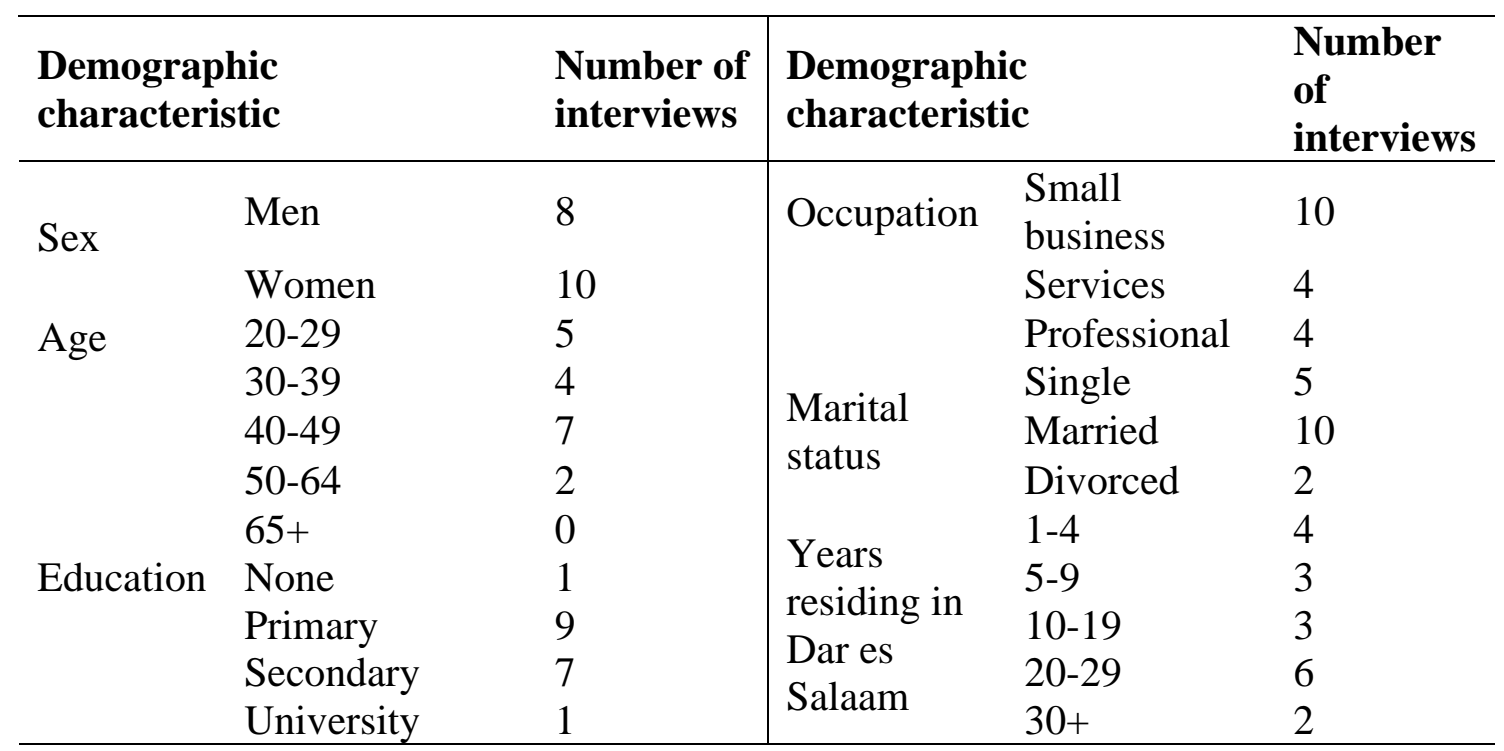


Table 5. Socio-demographic characteristics with respect to gender

\begin{tabular}{|c|c|c|c|c|c|}
\hline & Number of consumers & $\begin{array}{l}\text { Total } \\
123 \\
\end{array}$ & $\begin{array}{l}\text { Female } \\
59\end{array}$ & $\begin{array}{l}\text { Male } \\
64\end{array}$ & Probability $(\mathrm{p})$ \\
\hline \multicolumn{6}{|l|}{ Socio-demographic factors } \\
\hline Age range & $\begin{array}{l}1820 \\
2129 \\
3039 \\
4049 \\
5064 \\
65 \text { _or_older }\end{array}$ & $\begin{array}{l}10 \\
43 \\
36 \\
22 \\
10 \\
2\end{array}$ & $\begin{array}{l}5 \\
22 \\
14 \\
13 \\
5 \\
0\end{array}$ & $\begin{array}{l}5 \\
21 \\
22 \\
9 \\
5 \\
2\end{array}$ & 0.503 \\
\hline Marital status & $\begin{array}{l}\text { divorced } \\
\text { married } \\
\text { single }\end{array}$ & $\begin{array}{l}7 \\
72 \\
44\end{array}$ & $\begin{array}{l}6 \\
36 \\
17 \\
\end{array}$ & $\begin{array}{l}1 \\
36 \\
27\end{array}$ & 0.059 \\
\hline Education & $\begin{array}{l}\text { not } \\
\text { primary } \\
\text { secondary } \\
\text { university } \\
\text { Adult education }\end{array}$ & $\begin{array}{l}3 \\
42 \\
58 \\
19 \\
1 \\
\end{array}$ & $\begin{array}{l}1 \\
20 \\
28 \\
10 \\
0 \\
\end{array}$ & $\begin{array}{l}2 \\
22 \\
30 \\
9 \\
1 \\
\end{array}$ & 0.853 \\
\hline $\begin{array}{l}\text { Size of household (av.) } \\
\text { Under } 18 \mathrm{Y}\end{array}$ & & $\begin{array}{l}4.7 \\
1.6\end{array}$ & $\begin{array}{l}4.8 \\
1.7\end{array}$ & $\begin{array}{l}4.5 \\
1.4 \\
\end{array}$ & $\begin{array}{l}0.429 \mathrm{a} \\
0.363 \mathrm{a}\end{array}$ \\
\hline Type of household & $\begin{array}{l}\text { female headed } \\
\text { male headed }\end{array}$ & $\begin{array}{l}19 \\
104\end{array}$ & $\begin{array}{l}15 \\
44 \\
\end{array}$ & $\begin{array}{l}4 \\
60 \\
\end{array}$ & $0.003 *$ \\
\hline Are all 6-12 children in School & $\begin{array}{l}\text { no } \\
\text { we_do_not_have } \\
\text { yes }\end{array}$ & $\begin{array}{l}10 \\
37 \\
76 \\
\end{array}$ & $\begin{array}{l}3 \\
19 \\
37 \\
\end{array}$ & $\begin{array}{l}7 \\
18 \\
39 \\
\end{array}$ & 0.477 \\
\hline Are you a decision-maker for the family? & $\begin{array}{l}\text { no } \\
\text { yes }\end{array}$ & $\begin{array}{l}42 \\
81\end{array}$ & $\begin{array}{l}12 \\
47\end{array}$ & $\begin{array}{l}30 \\
34\end{array}$ & $0.002 *$ \\
\hline What is your job (classified)? & $\begin{array}{l}\text { Jobless } \\
\text { Professional } \\
\text { Skilled } \\
\text { Student } \\
\text { Unskilled }\end{array}$ & $\begin{array}{l}3 \\
16 \\
90 \\
7 \\
7\end{array}$ & $\begin{array}{l}1 \\
9 \\
41 \\
3 \\
5\end{array}$ & $\begin{array}{l}2 \\
7 \\
49 \\
4 \\
2\end{array}$ & 0.640 \\
\hline Do you own? & $\begin{array}{l}\text { a house } \\
\text { a car } \\
\text { a motobike } \\
\text { a bicycle }\end{array}$ & $\begin{array}{l}47 \\
11 \\
11 \\
16\end{array}$ & $\begin{array}{l}17 \\
5 \\
3 \\
8\end{array}$ & $\begin{array}{l}30 \\
6 \\
8 \\
8\end{array}$ & $\begin{array}{l}0.039 * \\
0.861 \\
0.15 \\
0.861\end{array}$ \\
\hline
\end{tabular}

Page | 26 


\begin{tabular}{|c|c|c|c|c|c|}
\hline & none & 66 & 39 & 27 & $0.008^{*}$ \\
\hline \multirow[t]{4}{*}{ Do you own (next)? } & a fridge & 78 & 38 & 40 & 0.826 \\
\hline & a TV & 108 & 54 & 54 & 0.226 \\
\hline & a radio & 107 & 50 & 57 & 0.477 \\
\hline & none & 7 & 4 & 3 & 0.617 \\
\hline \multirow[t]{2}{*}{ Are there tables in your house? } & no & 9 & 7 & 2 & 0.063 \\
\hline & yes & 114 & 52 & 62 & \\
\hline \multirow[t]{2}{*}{ Are there lanterns in your house? } & no & 83 & 41 & 42 & 0.647 \\
\hline & yes & 40 & 18 & 22 & \\
\hline \multirow[t]{2}{*}{ Do you have mains electricity } & no & 10 & 4 & 6 & 0.599 \\
\hline & yes & 113 & 55 & 58 & \\
\hline \multirow[t]{2}{*}{ Main fuel for cooking } & charcoal, paraffin, gas, electricity, generator etc. & 117 & 56 & 61 & 0.919 \\
\hline & $\begin{array}{l}\text { firewood, coal, solar, gas (biogas), wood/farm or } \\
\text { animal residuals }\end{array}$ & 6 & 3 & 3 & \\
\hline \multirow[t]{2}{*}{ House roofing material } & $\begin{array}{l}\text { corrugated iron sheets, cement/concrete, slate, asbestos } \\
\text { or roofing tiles }\end{array}$ & 117 & 56 & 61 & 0.919 \\
\hline & $\begin{array}{l}\text { grass/leaves/raffia/thatched wood, mud, bricks/earth, } \\
\text { bamboo or other }\end{array}$ & 6 & 3 & 3 & \\
\hline \multirow[t]{3}{*}{ Wall building material } & baked bricks & 39 & 20 & 19 & 0.599 \\
\hline & iron sheet, tiles, concrete or asbestos & 64 & 28 & 36 & \\
\hline & poles and mud, grass, sun-dried bricks or other & 20 & 11 & 9 & \\
\hline \multirow[t]{4}{*}{ Poverty Probability Index (PPI) } & Poverty score & 65 & 64 & 65 & $0.389 \mathrm{a}$ \\
\hline & Probability below National average & 4 & 4 & 4 & $0.558 \mathrm{a}$ \\
\hline & Probability below $\$ 2 /$ day & 28 & 26 & 27 & $0.408 \mathrm{a}$ \\
\hline & Probability below $\$ 5 /$ day & 83 & 80 & 82 & $0.224 \mathrm{a}$ \\
\hline \multirow[t]{2}{*}{ Nationality } & Other (Austrian + Congolese) & 2 & 1 & 1 & 0.954 \\
\hline & Tanzanian & 121 & 58 & 63 & \\
\hline \multirow[t]{2}{*}{ Do you live in Dar? } & no & 4 & 3 & 1 & 0.271 \\
\hline & yes & 119 & 56 & 63 & \\
\hline \multicolumn{2}{|l|}{$\begin{array}{l}\text { How long have you been living in Dar } \\
\text { (years) }\end{array}$} & 15.8 & 15.1 & 16.3 & 0.609 \\
\hline \multicolumn{2}{|l|}{ Proportion of life in Dar (av.) (calculation) } & $49 \%$ & $46 \%$ & $52 \%$ & 0.325 \\
\hline \multirow[t]{4}{*}{ Migration } & 'Natives' (born $<5$ year-old) & 11 & 15 & 26 & 0.605 \\
\hline & Settled young $(5-16$ year-old $)$ & 18 & 23 & 41 & \\
\hline & Settling in (more than 7 years in Dar) & 9 & 11 & 20 & \\
\hline & Newcomers (less than 7 years in Dar) & 18 & 14 & 32 & \\
\hline
\end{tabular}

Page | 27 
Table 6. Food choice attributes (developed by Steptoe et al. 1995) for staple food given by gender. Frequency was measured using the Check-all-

\begin{tabular}{|c|c|c|c|c|c|}
\hline Dimension & Attribute & Female & Male & Total & $\mathbf{p}$ \\
\hline \multirow{2}{*}{ 1.Health } & Nutritious & $22.0 \%$ & $32.5 \%$ & $54.5 \%$ & 0.063 \\
\hline & Gluten free & $1.6 \%$ & $0.0 \%$ & $1.6 \%$ & 0.138 \\
\hline \multirow{3}{*}{ 2.Mood } & Gives me strength & $26.0 \%$ & $30.1 \%$ & $56.1 \%$ & 0.690 \\
\hline & Poor man's food & $0.0 \%$ & $0.8 \%$ & $0.8 \%$ & 0.335 \\
\hline & Satisfying & $39.8 \%$ & $40.7 \%$ & $80.5 \%$ & 0.491 \\
\hline \multirow{4}{*}{ 3.Convenience } & $\begin{array}{l}\text { Can use in many different } \\
\text { dishes }\end{array}$ & $9.8 \%$ & $18.7 \%$ & $28.5 \%$ & 0.055 \\
\hline & Fills my stomach & $18.7 \%$ & $17.1 \%$ & $35.8 \%$ & 0.476 \\
\hline & Easy to cook & $25.2 \%$ & $30.9 \%$ & $56.1 \%$ & 0.446 \\
\hline & Easily available & $35.0 \%$ & $39.8 \%$ & $74.8 \%$ & 0.639 \\
\hline \multirow{3}{*}{ 4.Sensory appeal } & Smells nice & $28.5 \%$ & $27.6 \%$ & $56.1 \%$ & 0.489 \\
\hline & Looks nice & $29.3 \%$ & $29.3 \%$ & $58.5 \%$ & 0.592 \\
\hline & Good texture & $8.9 \%$ & $8.9 \%$ & $17.9 \%$ & 0.833 \\
\hline \multirow{6}{*}{$\begin{array}{l}\text { incl. sensory } \\
\text { description }\end{array}$} & Tastes good & $37.4 \%$ & $40.7 \%$ & $78.0 \%$ & 0.983 \\
\hline & Bitter & $0.0 \%$ & $0.0 \%$ & $0.0 \%$ & - \\
\hline & Sour & $0.0 \%$ & $0.0 \%$ & $0.0 \%$ & - \\
\hline & Sweet & $20.3 \%$ & $22.8 \%$ & $43.1 \%$ & 0.878 \\
\hline & Smooth & $0.8 \%$ & $4.9 \%$ & $5.7 \%$ & 0.066 \\
\hline & Dark & $0.0 \%$ & $0.0 \%$ & $0.0 \%$ & - \\
\hline 5.Natural content & Contains natural ingredients & $17.1 \%$ & $17.9 \%$ & $35.0 \%$ & 0.887 \\
\hline 6.Price & Not included & & & & \\
\hline 7.Weight control & Makes me lose weight & $1.6 \%$ & $1.6 \%$ & $3.3 \%$ & 0.934 \\
\hline \multirow{4}{*}{ 8.Familiarity } & Traditional food & $16.3 \%$ & $17.1 \%$ & $33.3 \%$ & 0.898 \\
\hline & The food is strange & $0.0 \%$ & $0.0 \%$ & $0.0 \%$ & - \\
\hline & New & $0.0 \%$ & $0.8 \%$ & $0.8 \%$ & 0.335 \\
\hline & Food of my childhood & $14.6 \%$ & $15.4 \%$ & $30.1 \%$ & 0.921 \\
\hline $\begin{array}{l}\text { 9. Ethical } \\
\text { concern }\end{array}$ & Not included & & & & \\
\hline
\end{tabular}

that-apply (CATA) test. A Chi2 test was used to detect significant differences at $\mathrm{p}<0.05$ between males and females Not included

Page | 28 
Table 7. Frequency and form of eating staple crop with respect to gender

\begin{tabular}{|c|c|c|c|c|c|}
\hline & & Total & Female & Male & \\
\hline \multirow[t]{4}{*}{ How often do you eat your staple crop? } & 3 times a day or more & 3 & 1 & 2 & 0.454 \\
\hline & 1-2_a_day & 95 & 46 & 49 & \\
\hline & 3 times a week & 23 & 10 & 13 & \\
\hline & once a week & 2 & 2 & & \\
\hline \multirow[t]{4}{*}{ In which form(s) do you eat your staple crop? } & boiled & 58 & 31 & 27 & 0.250 \\
\hline & ugali & 71 & 26 & 45 & $0.003^{*}$ \\
\hline & fried & 6 & 4 & 2 & 0.347 \\
\hline & roasted & 8 & 2 & 6 & 0.179 \\
\hline \multirow{3}{*}{$\begin{array}{l}\text { In which form(s) do you eat maize (if not your } \\
\text { staple)? }\end{array}$} & boiled & 11 & 5 & 6 & 0.171 \\
\hline & ugali & 61 & 39 & 22 & 0.687 \\
\hline & roasted & 1 & & 1 & 0.184 \\
\hline \multirow[t]{2}{*}{ In which form(s) do you eat rice? } & boiled & 83 & 34 & 49 & 0.407 \\
\hline & fried & 9 & 6 & 3 & 0.090 \\
\hline \multirow[t]{7}{*}{ How often do you eat cassava (if not your staple)? } & 3 times a day or more & 4 & & 4 & 0.306 \\
\hline & twice a day & 7 & 3 & 4 & \\
\hline & once a day & 52 & 28 & 24 & \\
\hline & 3 times a week & 15 & 6 & 9 & \\
\hline & once a week & 14 & 4 & 10 & \\
\hline & less than once a week & 10 & 6 & 4 & \\
\hline & less than once a month & 19 & 11 & 8 & \\
\hline \multirow[t]{5}{*}{ In which form(s) do you eat cassava? } & boiled & 50 & 24 & 26 & 0.990 \\
\hline & ugali & 63 & 30 & 33 & 0.942 \\
\hline & fried & 38 & 16 & 22 & 0.385 \\
\hline & raw & 8 & 4 & 4 & 0.904 \\
\hline & bread & 7 & 4 & 3 & 0.615 \\
\hline \multirow[t]{3}{*}{ Do you want to eat more cassava } & I do not know & 7 & 6 & 1 & 0.099 \\
\hline & no & 9 & 5 & 4 & \\
\hline & yes & 107 & 48 & 59 & \\
\hline
\end{tabular}

Note: the 'a' letter indicates that the test is a One-Way ANOVA; if there is no indication, it is a Chi-squared test 


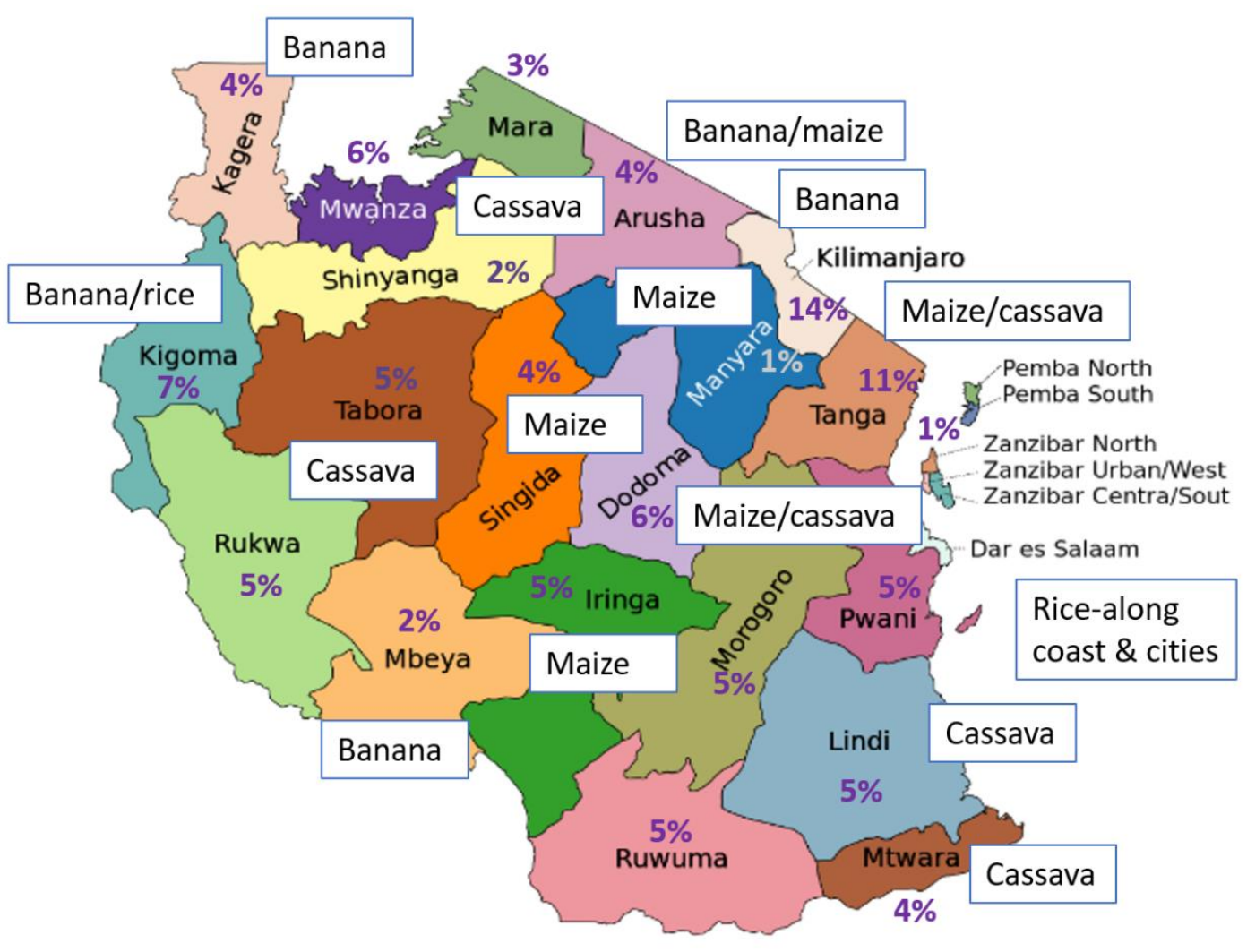

Figure 1. Main staple consumed by interviewees in their region of origin. Percentages of interviewees from each district from a total of 123 are indicated in purple (quantitative survey). Staples per region were defined in the qualitative survey 
Figure 2. Staple crop reported by female and male interviewees from different migration groups at formative years (up to the age of 16) and current staple (quantitative survey) (Chi-squared test $($ at $\mathrm{p}<0.05)$ indicates gender differences are $\mathrm{p}=0.02$ and $\mathrm{p}=0.01$ at formative and current years, respectively). Newcomers: in Dar es Salaam for less than 7 years; Settling-in migrants: in Dar for more than 7 years; Settled young (arriving in Dar between the age of 5 and 16 year-old; and 'Natives': born or been in Dar before the age of 5 .
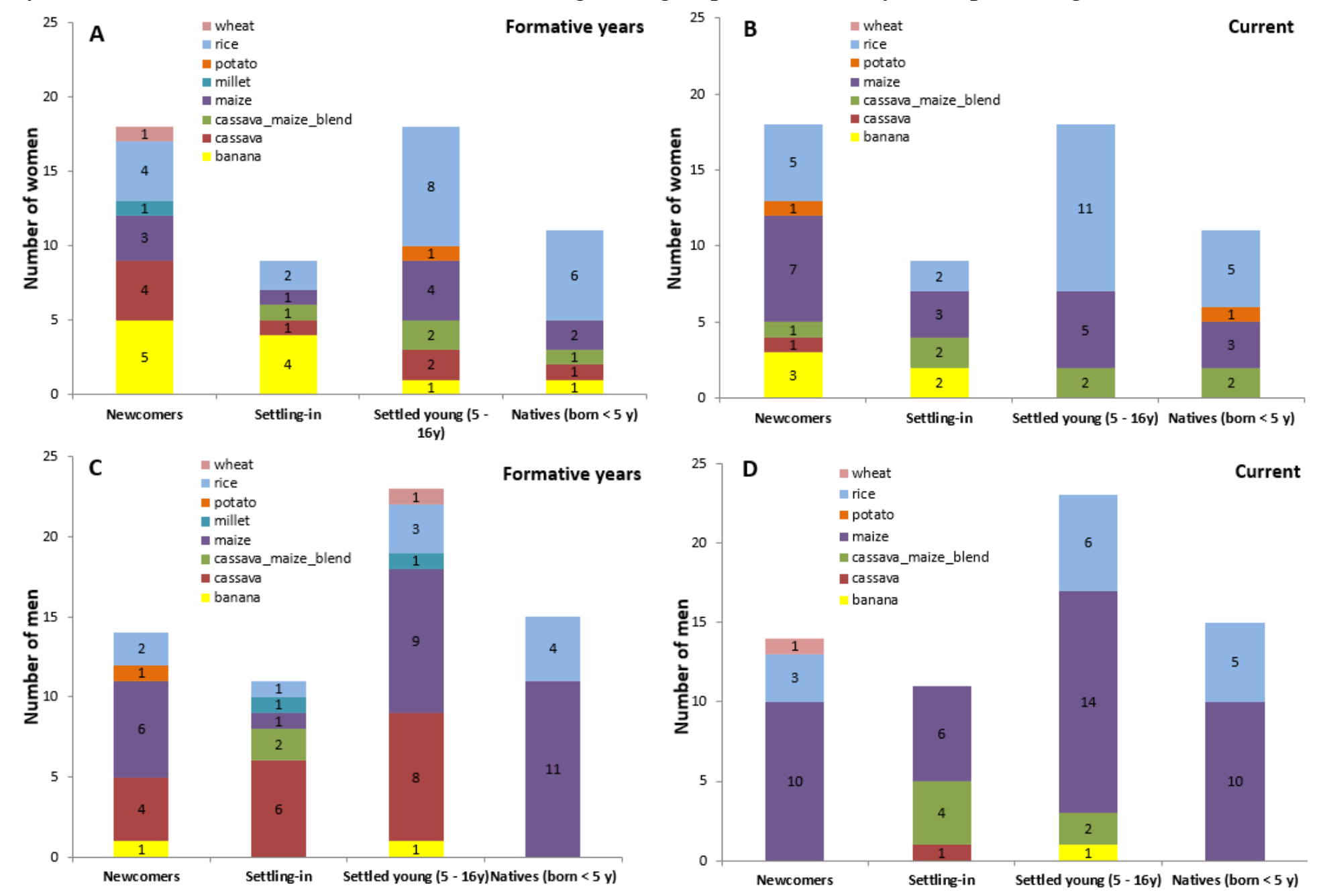